\title{
BASES ESENCIALES DE LA JUSTICIA RESTAURATIVA Y LOS PROGRAMAS DE REPARACIÓN DE LAS VÍCTIMAS
}

\author{
BASES ESSENCIAIS DA JUSTIÇA RESTAURATIVA E OS \\ PROGRAMAS DE REPARAÇÃO DAS VÍTIMAS
}

\section{ESSENTIAL BASES OF RESTORATIVE JUSTICE AND THE REPAIR PROGRAMS OF VICTIMS}

REYLER RODRÍGUEZ CHÁVEZ

Presidente de la Academia Mundial de Justicia Restaurativa. Magíster en Argumentación Jurídica por la Universidad de Alicante (España), Magíster en Derecho de la Empresa por la Pontificia Universidad Católica del Perú. Profesor de la Academia de la Magistratura de Perú. Juez Titular de la Corte Superior de Justicia de Lima Norte. Autor de trabajos y artículos científicos. E-mail: reyler6@gmail.com.

\section{TEÓFILO MARCELO DE ARÊA LEÃO JÚNIOR}

Post-DoctoradoenDerecho por ellus Gentium Conimbrigae, Facultad de Derecho, Universidad de Coimbra. DoctoradoenDerecho por lalnstitución Educativa de Toledo - ITE / Bauru-SP. Máster enDerecho de las Relaciones Sociales por laPontificiaUniversidad Católica de São Paulo - PUC-SP. Egresado de laFacultad de Derecho de Marília, hoy Curso de Derechodel Centro Universitario Eurípides de Marília - UNIVEM, mantenido por laFundación Eurípides Soares da Rocha. Líder del Grupo de Investigación: DerechosSocialesFundamentales - DIFUSUS. Autor de trabajos y artículos científicos. Profesor de Graduación y Máster enel Centro 
Universitario "Eurípides Soares da Rocha", de Marília / SP. Abogado. E-mail: teofilo@arealeao.com

\section{RESUMEN}

Objetivo: En el presente trabajo se desarrollan las bases esenciales de la Justicia Restaurativa como una disciplina con un contenido relevante y de especial incidencia ante situaciones conflictivas, en especial cuando se trata de reparar el daño causado a las víctimas, pues una de las razones y bases más trascedentes de esta rama, radica precisamente, en la tutela de la víctima y de sus derechos conculcados.

Metodología: El método utilizado es el deductivo, a través de una evaluación doctrinal de la literatura nacional y extranjera con respecto a los conceptos de justicia restaurativa, en particular los informes y directivas de las Naciones Unidas.

Resultados: A partir de la reparación integral del daño causado a las víctimas, se busca la restauración de una situación en función a la magnitud del daño causado, teniendo en cuenta el estatus de la víctima, velando por su adecuada y pronta atención, buscando que en el proceso restaurativo participen los involucrados, puesto que el problema es enfocado como generador de una grieta entre víctima y responsable, afectando a la estructura de la sociedad en general. De manera que, la mejor solución capaz de restaurar ese desequilibrio social causado por el conflicto, implica la coparticipación de víctimas, responsables y la comunidad, bajo un esquema de respeto de la libertad y los derechos humanos.

Contribuciones: El estudio ha contribuido a informar sobre las discusiones existentes sobre el tema de la justicia restaurativa como un mecanismo inclusivo que de manera independiente o complementaria al sistema de justicia, busca solucionar un conflicto y el daño producido por éste, mediante la coparticipación voluntaria, responsable y sensata de la víctima, el infractor y la comunidad.

Palabras clave: Justicia restaurativa, víctima, daño, reparación integral, proceso restaurativo, respeto de derechos humanos 


\section{RESUMO}

Objetivo: Neste trabalho, os fundamentos essenciais da Justiça Restaurativa são desenvolvidos como uma disciplina com conteúdo relevante e de incidência especial em situações de conflito, principalmente quando se trata de reparar os danos causados às vítimas, uma vez que uma das razões e bases mais importantes desse ramo residem justamente na proteção da vítima e de seus direitos violados.

Metodologia: O método utilizado é o dedutivo, por meio de uma avaliação doutrinária de literatura nacional e estrangeira a respeito de conceitos de justiça restaurativa, em especial os informes e diretivas da Organização das Nações Unidas.

Resultados: A partir da reparação integral dos danos causados às vítimas, busca-se a recuperação de uma situação com base na magnitude dos danos causados, levando em consideração o status da vítima, garantindo sua atenção adequada e imediata, buscando que os envolvidos participem do processo restaurador, uma vez que o problema é tratado como gerador de uma brecha entre vítima e responsável, afetando a estrutura da sociedade em geral. A melhor solução capaz de restaurar esse desequilíbrio social causado pelo conflito implica a coparticipação das vítimas, dos responsáveis e da comunidade, em um esquema de respeito à liberdade e aos direitos humanos.

Contribuições: $O$ estudo contribuiu para relatar as discussões existentes sobre o tema da justiça restaurativa como um mecanismo inclusivo que independentemente ou complementar ao sistema judiciário, procura solucionar um conflito e os danos causados por ele, por meio da participação voluntária, responsável e sensata da vítima, do agressor e da comunidade.

Palavras-chave: Justiça restaurativa; vítima; dano; reparação integral; processo restaurativo.

\section{ABSTRACT}

Objective: In this paper the essential foundations of restorative justice as a discipline with relevant content and special incidence are developed in conflict situations, especially when it comes to repairing the damage caused to the victims, as the reasons and most important bases of this branch is precisely in the guardianship of the victim and the violated rights. 
Methodology: The method used is the deductive one by way of a doctrinal evaluation of national and foreign literature regarding concepts of restorative justice, especially the reports and directives of the United Nations.

Results: From the reparation of the damage caused to the victims, seeks the restoration of a situation based on the magnitude of the damage, taking into account the status of the victim, ensuring the adequate and prompt attention, pursuing the participation of the involved parties in the restorative process, since the problem is focused as a generator of a rift between victim and offender, affecting the structure of society in general. The best solution capable of restoring this social imbalance caused by the conflict involves the co-participation of victims, offenders and the community, under a scheme of respect for freedom and human rights.

Contributions: The study has contributed to reporting on existing discussions on the subject of restorative justice as an inclusive mechanism that independently or complements the justice system, seeks to solve a conflict and the damage caused by it, through voluntary co-participation, responsible and sensible of the victim, the offender and the community.

Keywords: Restorative justice; victim; damage; integral reparation; restorative process.

\section{INTRODUCCIÓN}

La evolución de los sistemas de justicia para reprimir ilícitos penales, en las últimas décadas ha puesto en cuestionamiento la vigencia y eficacia del rol que cumple el proceso penal de molde retributivo, frente a la persecución del delito, la represión de los responsables y el restablecimiento de la paz social. RULLAN señala que, "[...] desde la óptica retributiva se plantea resolver quien tiene la razón y quien tiene la culpa, así como dar su merecido al culpable, hacer que pague por lo que ha hecho, a fin de que no vuelva a hacerlo y que la sanción sirva de ejemplo disuasorio para la comunidad" (RULLAN CASTANER, 2011, p.14). 
En este mismo sentido BILBAO precisa que conforme a este esquema el victimario esel protagonista principal y, "lo que verdaderamente importa es qué se hace con él y cuál el castigo que corresponde imponerle y con cuyo cumplimiento salda las deudas que tiene contraídas con la sociedad y con sus víctimas directas" (BILBAO ALBERDI, 2013, p.200).

Sin embargo, la idea de reprimir el mal causado por el infractor, mediante la imposición de otro mal -pena o castigo-, en la práctica, ha venido dando resultados poco alentadores no sólo desde el punto de vista del infractor sino también desde el punto de vista de la víctima y la comunidad.

El infractor, luego que ha padecido el castigo impuesto por los tribunales, carece de los medios necesarios para redimirse socialmente y emprender una nueva vida pese a que ya pagó por el daño; por el contrario, inmediatamente es estigmatizado en su entorno social. Para él la idea de resocialización o reinserción le es vedada debido muchas veces a las deficiencias del propio sistema legal congestionado, que desvincula al condenado dejándolo a su suerte pero con el estigma de "asesino", "ladrón", "estafador", "peligroso", etc., cuyo efecto inmediato es la exclusión social.

Quien ha tenido el infortunio de ser sometido al sistema represivo, sabe que la sanción no termina con la pena impuesta, sino que el estigma lo perseguirá durante mucho tiempo, e incluso, de por vida.

La secuelas posteriores al castigo son tan iguales o más graves que aquellas padecidas al cumplir la sanción.

Al respecto, WELZEL señala que, "no es suficiente para aclarar el sentido de la pena, como un mal merecido por la violación culpable del derecho, cuando la ejecución del mal hace al condenado peor de lo que era" (BACIGALUPO, 1999, p.269) Así entonces, muchas veces el remedio -imposición de una sanción-, termina siendo peor que la enfermedad: Sentenciado no rehabilitado y excluido, con más propensión al delito que a la abstención. 
El tratamiento del sistema retributivo resulta tan traumático en ciertos casos, lo cual de por sí disminuye las posibilidades de reinserción y rehabilitación de los catalogados como delincuentes o criminales.

Para la víctima, el sometimiento a un proceso penal le ha significado constante padecimiento moral y económico, que incluso se va sumando al ya vivido al momento del crimen, y que a la larga es difícilmente reparado. Su participación en el conflicto importa un "vía crucis" permanente cuyo fin es incierto e impredecible, y que terminará por someter aún más su estatus de ciudadano deteriorado por el delito, a un conjunto de trámites y trabas burocráticas que no hacen más que desalentar las pocas esperanzas de ser compensado por los daños sufridos.

La víctima bajo el sistema retributivo vive en constante desaliento y desamparo legal y moral. Una vez involucrada en el sistema, requiere hacer efectivo su reclamo que pocas veces es atendido, pues para lograr ello debe emprender una lucha agotadora y que le demandará innumerables gastos y preocupaciones.

Al respecto BILBAO indica que bajo el modelo retributivo las víctimas carecen de protagonismo: "En el proceso judicial apenas son tenidas en cuenta, muchas veces figuran simplemente como meros testigos y la información que reciben de todo el procedimiento es frecuentemente escasa, si no inexistente. De algún modo podría decirse que con la intervención de la justicia penal la víctima lo transfiere todo al Estado y su sistema judicial para que él «arregle cuentas» con el infractor" (BILBAO ALBERDI, 2013, p.200).

De esta manera, la relación derivada del delito y que vinculaba directamente a la víctima frente a su agresor, le es expropiada para ser conducida por el sistema punitivo del Estado, dejando a la víctima prácticamente como mero espectador del conflicto en el que fue parte, donde sufrió las consecuencias y respecto al cual espera algún tipo de resarcimiento. 
Entre la víctima y el responsable existe una barrera -proceso penal- llena de procedimientos y formalidades, que muchas veces obstaculizan escuchar con claridad y oportunidad sus reclamos y pedidos.

Al respecto DUYMOVICH señala que, "en los esquemas de la Justicia Retributiva que se vincula estrechamente con los fines de la pena, lo importante es dar un mensaje al sancionado, a posibles infractores y a la sociedad, bajos los tradicionales criterios de prevención especial y general. Así, la víctima del delito es olvidada y sólo se van a acordar de ella en la reparación civil"1.

En el modelo retributivo, el Estado se irroga la potestad de sancionar conforme "sus intereses y principios", dejando de lado los intereses, necesidades y sentimientos de los directamente perjudicados.

Para la comunidad, el regreso de un sujeto lleno de rencores y remordimientos, frustración y marginación; significa un riesgo constante de reincidencia y genera una sensación permanente de inseguridad en el resto de ciudadanos, quienes se sienten desprotegidos y viven atemorizados, pues desconfían en las instituciones encargadas de su protección y están desalentados para reclamar por sus derechos y denunciar alguna agresión².

Las deficiencias del modelo retributivo terminan por generar un sentimiento colectivo de inseguridad y falta de solidaridad con los demás miembros del espacio

1 DUYMOVICH ROJAS, 2007, p.9: Esta situación se evidencia por un estudio realizado por el Poder Judicial Peruano donde se concluye que: Al término del año 2013, un número de 500 usuarios encuestados señalan que tienen que acudir a las sedes del Poder judicial de "manera frecuente", un $27 \%$ acude de veintiún a treinta veces al mes, el $23 \%$ de once a veinte veces y el $14 \%$ de seis a diez veces. Asimismo, el $53 \%$ de los usuarios se sienten poco satisfechos con la atención recibida por el Poder Judicial y el $14 \%$ de usuarios se sienten nada satisfechos. Entre los principales motivos de la insatisfacción, el $76 \%$ se siente insatisfecho por la demora en la atención, un $29 \%$ porque la atención deficiente y un 13\% por la demora de los funcionarios; Cfr., PODER JUDICIAL DEL PERU, 2013, pp. 14,25 y 27.

${ }^{2}$ En nuestro país se ha determinado a Diciembre del 2015 lo siguiente: A nivel nacional urbano, la población de 15 y más años de edad, que fue víctima de algún hecho delictivo, no denuncia el hecho principalmente porque desconoce al delincuente $(30,3 \%)$, y porque consideran que es una pérdida de tiempo $(26,7 \%)$, en las ciudades de 20 mil a más habitantes el principal motivo por el cual la población no denuncia el hecho es porque manifiestan que desconoce al delincuente (29,7\%), seguido del motivo es una pérdida de tiempo $(28,0 \%)$, Cfr., INSTITUTO NACIONAL DE ESTADISTICA E INFORMATICA, 2016, p. 6. 
social, pues nadie está dispuesto a correr el riesgo de apoyar en la reformación de un sujeto que no da ninguna muestra de cambio positivo.

De esta manera, el resultado final de un sistema penal retributivo es el desamparo de los responsables y víctimas, quienes luego de culminar un proceso penal, al incorporarse a la sociedad han dejado de ser los mismos, pues ambos desde su particular situación, han pasado momentos sumamente duros, cuyos efectos son trasladados a su entorno social.

Ello pone en evidencia que la solución emprendida desde este modelo, requiere la reestructuración de sus bases pues no produce los resultados deseados en la comunidad: prevención, paz y seguridad.

\section{DEFINICIÓN DE JUSTICIA RESTAURATIVA}

La justicia restaurativa es un mecanismo inclusivo que de manera independiente o complementaria al sistema de justicia, busca solucionar un conflicto y el daño producido por éste, mediante la coparticipación voluntaria, responsable y sensata de la víctima, el infractor y la comunidad. Se considera al delito como un daño que el infractor ha causado a la víctima y a la sociedad, en tal sentido, lo más adecuado es que sean los propios involucrados quienes encuentren la mejor solución frente a las repercusiones derivadas del conflicto.

Uno de los pioneros en el tema, MARSHALL señala que, "la justicia restaurativa es un proceso en el que las partes que tienen que ver con un acto perjudicial deciden colectivamente como van a abordar las consecuencias del acto y sus implicaciones de cara al futuro" (RULLAN CASTANER, 2011, p.7).

Para ZEHR, "la justicia restaurativa es un proceso a través del cual el infractor, con remordimientos por su conducta, acepta su responsabilidad hacia quien ha dañado y hacia la comunidad, que en respuesta a ello permite la 
reintegración del ofensor en la comunidad. El énfasis se pone en la restauración: Restauración del ofensor en términos de auto-respeto, restauración de la relación entre la víctima y el ofensor, y también restauración de ambos dentro de la comunidad" (OLALDE, 2006, p.7).

La justicia restaurativa busca poner el conflicto en manos de los directamente interesados, para que sean éstos precisamente los que encuentren una solución que satisfaga sus intereses. Pues los mecanismos empleados por el sistema estatal de base retributiva, imponen soluciones marginales a las necesidades y expectativas de la víctima, el infractor y la comunidad.

En la justicia restaurativa se busca restablecer las relaciones buscando soluciones pacíficas y conjuntas que beneficien a todos los involucrados. En ese sentido la justicia restaurativa es un proceso colectivo e inclusivo ${ }^{3}$.

Bajo este contexto, VAN NESS y HEETDERKS precisan que la justicia restaurativa, "se enfoca en el daño causado por la delincuencia, reparándolo en las víctimas y reduciéndolo en el futuro mediante la prevención de la delincuencia. Para esto se requiere que los delincuentes tomen la responsabilidad de sus actos y del daño que causaron y busquen en conjunto con las víctimas, y los miembros del entorno social su reintegración a la sociedad" (FRÍAS ARMENTA; ÁLVAREZHERNÁNDEZ, 2015, p. 7).

Desde nuestra perspectiva, la justicia restaurativa se ha consolidado sobre una plataforma esencial conformada por dos elementos esenciales: Una "base plurisubjetiva" que la integran los sujetos afectados por el conflicto derivado del delito, así como por la necesidad de tutela y respeto adecuado de sus derechos, intereses y expectativas; $\mathrm{y}$, por una "base pluriobjetiva" compuesta por las consecuencias derivadas del delito en la víctima, el infractor y la comunidad, así

\footnotetext{
${ }^{3}$ En este sentido se precisa que la justicia restaurativa "(...) pone en práctica el hecho de que las partes son dueñas de su conflicto, y se les da la oportunidad de resolverlo de la mejor manera para ellos y para el retorno de la paz social. Se trata de crear un balance entre el aspecto individual y el social, y por ello se ha hecho referencia en doctrina a la justicia restaurativa, como una experiencia democrática", Véase: HIDALGO PORRAS, 2012, p. 45.
} 
como por los medios empleados para lograr la reparación integral del daño ocasionado.

\section{BASES ESENCIALES DE LA JUSTICIA RESTAURATIVA}

\subsection{BASE PLURISUBJETIVA}

La justicia restaurativa tiene una "base plurisubjetiva" porque el enfoque del sistema penal ya no se centra exclusivamente en la persona del infractor, sino también y en igual magnitud, en la persona de la víctima, como directos afectados. Pero esta visión también considera a los familiares y amigos de las partes, y hasta a la comunidad, como afectados e interesados en la resolución del conflicto.

Con la justicia restaurativa se busca reconocer y determinar que existe un autor del delito, un responsable del daño que además es capaz de reconocerlo y de hacerse cargo del mismo, pero también, hay que identificar y tutelar a la persona que ha padecido el sufrimiento de la acción penal, al sujeto dañado directamente y a la comunidad remecida por la inconducta del agente lesivo. Lo esencial es considerar que los involucrados, al estar ligados por el daño causado, consecuentemente, todos de algún modo deben coadyuvar en su tratamiento y reparación, para que la solución que se alcance sea la más integral.

Hay que entender que la víctima y el ofensor no son sujetos aislados, son por el contrario, parte de una colectividad, por tal motivo, lo que suceda con ellos, tarde o temprano, terminará por afectar también a la sociedad en su conjunto.

La base plurisubjetiva hace que la justicia restaurativa constituya un proceso de carácter humano, integral, reparador y comunitario.

En este sentido BRITTO señala que la justicia restaurativa, "busca restaurar el lazo social dañado por la acción criminal en un proceso de reparación y 
reconciliación entre la víctima y el infractor, con la mediación de la comunidad. Cuestiona la abstracción del modelo jurídico y apela al conocimiento y resolución de los conflictos entre sujetos concretos de comunidades concretas. Da un papel fundamental a la víctima a quien se repara el daño y responsabiliza al ofensor, además de darle la oportunidad de deshacer el daño y reconciliarse con la sociedad" (BRITTO RUIZ, 2010, p.14).

La Organización de las Naciones Unidas también se ha pronunciado sobre los alcances de la justicia restaurativa señalando que, "según el concepto de justicia restaurativa, un delito suele afectar no sólo al futuro de las víctimas y comunidades, sino también al de sus autores. La justicia restaurativa procura restablecer los intereses de todas las partes afectadas por un acto delictivo, en la medida de lo posible con la participación activa y voluntaria de los delincuentes, las víctimas y las comunidades" (ORGANIZACIÓN DE LAS NACIONES UNIDAS, 2002, p. 3).

Desde la perspectiva del infractor, se busca que éste no sólo participe del proceso restaurativo sino que lo haga con iniciativa, de manera voluntaria y con el compromiso necesario para asumir las responsabilidades que se le encomienden para reparar el daño que causó.

Como precisa SUBIJANA (2012, p. 148): "[...] al infractor le comunica que ha cometido un hecho que ha causado un daño injusto a una o varias personas. Por tal motivo desaprueba su conducta y le exige llevar a cabo todo lo que está en sus manos para restañar el daño".

Desde la perspectiva de la víctima, la justicia restaurativa procura la reparación integral del daño sufrido, lo cual comprende no solo la restitución de los daños materiales, sino también la reparación de los daños inmateriales, como el tratamiento de las secuelas psicológicas, la ansiedad y sensación de desprotección e inseguridad, el sufrimiento constante y la frustración.

En este caso, la tutela y protección de la víctima es uno de los temas de principal preocupación para la justicia restaurativa, de modo que su bienestar y 
reparación son temas centrales de toda iniciativa (CARRANCA Y TRUKILLO, 2015M p.649).

Finalmente, desde la perspectiva de la comunidad, la justicia restaurativa busca mejorar la seguridad y la paz en los ciudadanos, pues la composición de los conflictos con la coparticipación de la víctima, el infractor y la comunidad, tiene efectos positivos en la prevención y evita a reincidencia de nuevos hechos delictivos, y además, la rehabilitación del infractor se realiza de manera efectiva.

Al respecto SUBIJANA señala que "el compromiso comunitario exige una involucración de la sociedad en la tarea de reconstrucción de lo deteriorado por el delito, pues la infracción es, también, un conflicto social que la comunidad tiene que resolver con la mayor eficacia y la menor aflicción" (SUBIJANA ZUNZUNEGUI, 2012, p.149).

Para FRIEDMAN, la manera de deshacer el impacto negativo que el delincuente ha generado, es arrepintiéndose de todo el daño causado a la víctima y a la comunidad, lo que se ha denominado "vergüenza reintegrativa" (FRIEDMAN VOLOSKY, 2007, p.3).

\subsection{BASE PLURIOBJETIVA}

Por otro lado, la "base pluriobjetiva" de la justicia restaurativa busca en primer término, determinar las dimensiones y la gravedad del daño causado por la comisión de la acción delictiva, a fin de tener plena certeza del problema que habrá de resolverse y sobre todo, si por las características del mismo, es susceptible de ser sometido al tratamiento de la justicia restaurativa. Pues habrán hechos que dada su enorme gravedad, la falta de voluntad de la víctima o la inmutabilidad del infractor, serán de difícil conducción mediante un mecanismo restaurativo. Tal será el caso de un asesino en serie o el caso de una víctima de violación sexual que se 
niega a participar de un proceso restaurativo, en estos supuestos, es el sistema de justicia tradicional que se encargará de llevar a cabo el proceso respectivo.

En segundo lugar, la base "base pluriobjetiva" de la justicia restaurativa busca que se consideren todas las consecuencias posibles derivadas del daño, tanto para la víctima, el infractor y la comunidad.

\subsubsection{Para la víctima}

Desde la posición de la víctima, se ha de buscar que el infractor reconozca del daño causado como consecuencia de su accionar ilícito, que él mismo sea consciente de la magnitud del daño y de las consecuencias que éste ha causado en la víctima y la comunidad. Asimismo, ha de buscarse que el infractor de manera responsable se comprometa a la "reparación integral del daño".

Como precisa SUBIJANA, "a la víctima le traslada que el daño injusto que ha sufrido no es fruto del azar o de un caso fortuito sino consecuencia del comportamiento de una o varias personas. Por ello le reconoce el derecho a ser reparada" (SUBIJANA ZUNZUNEGUI, 2012, p. 148)4.

A la víctima lo que le importa inmediatamente es que el menoscabo sufrido como producto de la conducta lesiva sea reparado, pues antes de que sucediera aquél hecho dañoso, no soportaba ni asumía ningún daño, pero que ahora se ve obligada a hacerlo.

Pero habrá de comprenderse dentro del daño no sólo la restitución de las cosas materiales, sino también se buscara minimizar las secuelas morales y sicológicas que dejó el trauma delictivo en la víctima.

\footnotetext{
${ }^{4}$ Al respecto CESANO señala que "la reparación del daño es más bien, la solución objetiva o simbólica que restituye la situación al estado anterior a la comisión del delito, satisfaciendo a la víctima, pudiendo ser la devolución de la cosa hurtada, una disculpa pública o privada, trabajo gratuito, entre otros", Cfr., PÉREZ SAUCEDA; ZARAGOZA HUERTA, 2015, p. 12.
} 


\subsubsection{Para el infractor}

Se buscará que el infractor reconozca y asuma la magnitud y los efectos del daño causado, que acepte que el daño es consecuencia directa de su mal accionar, y que es el primer llamado a repararlo. En esta fase el infractor, cual niño que ha roto una vasija costosa de la sala y que se halla frente a la madre, se encuentra frente a frente con la víctima y con el daño que ha causado.

Esto permite sincerar y observar la cruda realidad del daño para el infractor, lo cual hace mucho más fácil que éste asuma su responsabilidad por el daño. Al respecto se exige que: "El infractor haga suyo el delito cometido -el delito le pertenece, aunque no le define-, reparando lo destruido o deteriorado y, desde esta asunción, inicie un cambio de orientación vital que le aleje del delito. Ser consciente de que el delito ha perturbado severamente el orden existencial de la víctima $y$, desde esta consciencia, desarrollar conductas de restañamiento del daño causado, constituye la manifestación más seria de una dinámica de inserción social constructiva" (SUBIJANA ZUNZUNEGUI, 2012, p.148-149).

En este contexto, también se buscará que el infractor participe de un procedimiento restaurativo que le otorgue un trato humano y digno, donde se respeten sus derechos humanos, donde se proscriba cualquier tipo de estigmatización, donde se le conceda alternativas de redención, donde exista posibilidad de disminución de la pena, la aplicación de penas alternativas a la privación de la libertad, la posibilidad de culminar el conflicto fuera o dentro del proceso penal, la concesión de facilidades para reparar el daño, etc. 


\subsubsection{Para la comunidad}

La base pluriobjetiva de la justicia restaurativa en lo que respecta a la comunidad, busca el establecimiento de mecanismos adecuados y eficaces para lograr la rehabilitación del infractor, que le permitan tomar conciencia de sus malas acciones, que le faciliten redimirse mediante la reparación del daño social, solicitando el perdón público o privado, cumpliendo medidas como la prestación de servicio social, integrando redes de prevención, u otra forma que efectivice la restitución de la paz social.

Al respecto, HIDALGO se refiere a "hacer una enmienda", pues señala que, "no solamente se pretende la reparación o restitución del daño, sino la toma de acciones necesarias para un cambio, y esa decisión de cambio para la vida de la persona ofensora, tiene de forma directa un impacto en la disminución de la reincidencia, lo que podría incluir otros compromisos extra de parte del imputado o imputada como una disculpa, un trabajo comunal, terminar sus estudios, entre otros"5.

Debe precisarse que la base "base pluriobjetiva" de la justicia restaurativa busca primordialmente la "reparación integral" del daño causado, considerando todas las consecuencias posibles derivadas del daño, tanto para la víctima, el infractor y la comunidad. Pues mientras más completa sea la solución del problema tomando en cuenta todas sus dimensiones, mayor será el nivel de restauración de las relaciones sociales.

Así entonces, la "base plurisubjetiva" y la "base pluriobjetiva" son inseparables y constituyen la esencia misma de la justicia restaurativa. Los sujetos afectados por el daño (víctima, infractor y comunidad), son los más indicados e

${ }^{5}$ HIDALGO PORRAS, 2012, p. 22. AL respecto, SUBIJANA señala que el compromiso comunitario exige una involucración de la sociedad en la tarea de reconstrucción de lo deteriorado por el delito, pues la infracción es, también, un conflicto social que la comunidad tiene que resolver con la mayor eficacia y la menor aflicción, SUBIJANA ZUNZUNEGUI, 2012, p. 149. 
interesados para solucionar los efectos de la acción ilícita (daño), y esta simbiosis de solución, representa la manera más eficaz para restaurar las relaciones afectadas, en procura del bienestar general.

Como podernos observar, la justicia restaurativa es un medio de coparticipación de diversos interesados cuyo fin último es la reparación integral de los daños causados por la comisión de acciones delictivas. Si bien se pone el acento en la reparación de la víctima por el daño sufrido, no es menos cierto que el daño también produce efectos en el infractor, que van desde el hecho de asumir la magnitud del daño, el compromiso del repararlo, así como la predisposición para redimir su comportamiento ante la sociedad mediante actos concretos como expresiones de perdón público o privado, la realización de labores comunales, entre otras. Y, para la comunidad, una efectiva rehabilitación del infractor permitirá reforzar la seguridad y protección de los ciudadanos, evitar los casos de reincidencia y fortalecer la prevención.

Sobre este punto, para SAMPEDRO lo que se busca con la justicia restaurativa es lograr las " 3 r's":

a) Responsabilidad por parte del ofensor, porque cada persona debe responder por sus acciones $u$ omisiones. b) Restauración de la víctima, quien necesita ser reparada. Requiere abandonar su posición de dañado, así como toda la sociedad. c) Reintegración del infractor, quien necesita restablecer los vínculos con la sociedad, que a su vez, necesita del buen desempeño de todos sus integrantes para su correcto funcionamiento (PÉREZ SACUEDA; ZAEAGOZA HUERTA, 2015, p.640-641).

Lo señalado no hace sino reforzar la idea de que la justicia restaurativa reúne el trinomio compuesto por "víctima-infractor-comunidad" con el fin de lograr un objetivo común cuyo trinomio es a su vez: "daño-reparación-rehabilitación". 


\section{LA JUSTICIA RESTAURATIVA COMO UN MEDIO DE REPARACIÓN}

Partiendo de la definición de la justicia restaurativa así como de los elementos esenciales que la conforman, es decir la base plurisubjetiva y la base pluriobjetiva, podemos establecer algunas cualidades de la justicia restaurativa que la convierten en una herramienta importante en la atención y reparación de la víctima y del conflicto.

\subsection{ES UN PROCESO INTERSUBJETIVO}

La justicia restaurativa como se ha puesto en relieve, es un mecanismo que necesariamente se efectiviza con la participación de un trinomio compuesto por víctima-infractor-comunidad, de allí que sostengamos la existencia de una base plurisubjetiva de la justicia restaurativa. Ello considerando las diversas variantes en aquellos procesos restaurativos que involucran la participación más activa de víctima, el infractor y de la comunidad.

La justicia restaurativa pone énfasis en el elemento subjetivo, es decir en, el trinomio: Víctima-infractor-comunidad, como el principal factor para encontrar la mejor y más efectiva solución al daño causado por la acción criminal, pues no habrá mejor solución que aquella que de mutuo propio acuerden los directamente involucrados en el conflicto, con el acompañamiento y soporte de la comunidad 6 .

${ }^{6}$ Sobre el tema, MCEVOY y NEWBURN señalan que, la teoría se enfoca a la restauración y el alivio de las víctimas y la participación de la comunidad, en lugar de la retribución, que enfatiza lo incorrecto de la conductadel delincuente y la exclusividad de la atención profesional y del estado. (FRÍAS ARMENTA; ÁLVAREZ-HERNÁNDEZ, 2015, p. 4). 


\subsection{ES UN PROCESO VOLUNTARIO}

La participación de la víctima y del infractor, principalmente, así como de los amigos, familiares y representantes de la comunidad, se hace por decisión propia. Las partes tienen plena libertad de decidir su participación en un proceso de justicia restaurativa. La mejor forma solucionar el problema con sensatez y compromiso, es permitiendo a las partes la posibilidad de participar libre y voluntariamente, de manera que puedan iniciar, suspender o dar por terminado el proceso cuando lo crean conveniente.

Toda medida que se adopte contra la voluntad de las partes, no hará otra cosa que producir un resultado similar al de los sistemas tradicionales de justicia, una solución parcial, que deja de lado los intereses de la víctima, que es ejecutable parcialmente, que no posibilita la rehabilitación del infractor y cuyos efectos preventivos son casi inexistentes.

Por el contrario, una solución voluntaria entre víctima e infractor, antecedida de una secuela de tratos y entendimiento entre las partes, con reconocimiento de responsabilidad, intercambio de antecedentes, vivencias y la expresión directa de los efectos negativos producidos por la conducta delictiva en cada una de las partes; todo ello permite que la solución genere un real compromiso para el infractor de reparar el daño, para la víctima una mayor certeza de que eso suceda, y para la comunidad la sincera y efectiva rehabilitación del infractor permite el fortalecimiento de las relaciones sociales, otorga mayor garantía de seguridad a los ciudadanos y sirve en la prevención del delito? ${ }^{7}$.

La voluntariedad en las partes que intervienen en un proceso restaurativo, es un elemento clave para lograr los resultados buscados por la justicia restaurativa: El

\footnotetext{
${ }^{7}$ En la Asamblea de las Naciones Unidas, los países de Bolivia y Estados Unidos pusieron énfasis en la participación voluntaria de las partes con el fin de llegar a acuerdos razonables y proporcionados, subrayando la importancia de permitir a las víctimas decidir si participan o no, su grado de participación y decidir si dejarían de participar, Cfr., ORGANIZACIÓN DE LAS NACIONES UNIDAS, 2002 , p. 7.
} 
infractor tendrá mayor libertad para comprender el daño causado y sus efectos, generando en él mayor compromiso al momento de la reparación y el cumplimiento de las tareas tendientes a su rehabilitación. La víctima que participa con voluntad en un proceso restaurativo, tendrá mayores posibilidades de lograr la "reparación integral" del daño sufrido, sobre todo de las secuelas psicológicas causadas por el trauma delictivo, al estar predispuesta a aceptar las disculpas y conceder el perdón al infractor.

La participación libre de los amigos, la familia o de ciertos miembros de la comunidad, ayuda a fortalecer el compromiso y la reparación del daño, así como restablece los lazos sociales alterados.

\subsection{ES UN PROCESO PRO VÍCTIMA}

Uno de los pilares del surgimiento de la justicia restaurativa se halla en la necesidad de tutela de la víctima, cuyos derechos, intereses, necesidades y expectativas, por muchos años habían sido postergados a la luz del sistema penal retributivo. Con la justicia restaurativa, la víctima deja la marginación y el desamparo, pasando de ser un agente meramente espectador a un sujeto protagónico y esencial.

La justicia restaurativa halla su razón de ser en la necesidad de restituirle a la víctima todo aquello que le fue arrebatado por la acción delictiva; pues la víctima al formar parte de la comunidad, refleja en el entorno social las consecuencias perniciosas que causó el delito.

Al respecto REYES MATE señala que, "la justicia de la víctima supone reconocer que posee una mirada singular de la realidad y que lo que es así visto forma parte de la realidad. En concreto, la víctima ve algo que escapa al verdugo y al espectador: El significado del sufrimiento declarado insignificante para la cultura dominante" (SUBIJANA ZUNZUNEGUI, 2012, p.148). 
La justicia restaurativa se ocupa de ver las consecuencias del delito a través de los ojos de la víctima, prioritariamente, en lugar de hacerlo a través de los ojos del infractor o del Estado, como sucede en los sistemas penales de molde retributivo.

Bajo el contexto de la justicia restaurativa, inmediatamente de ocurrido el delito, hay que acoger a la víctima para protegerla y atenuar los daños causados, procurando su inmediata atención física y psicológica hasta su recuperación, brindándole constante acompañamiento y fuerza moral, otorgándole adecuada y oportuna consejería y asesoría para el ejercicio de sus derechos vulnerados; y, facilitarle los medios necesarios para que pueda ser reparada por los daños sufridos.

La importancia de la víctima para la justicia restaurativa, ha llevado a desarrollar importantes programas de asistencia a las víctimas, que como indican PEREZ y ZARAGOZA, están destinados a la recuperación que han sufrido por el daño causado. Estos programas se dividen en dos grandes apartados, la defensa de los derechos de las víctimas y los servicios de asistencia materiales y psicológicos. Los objetivos que persiguen estos mecanismos son los siguientes:

a) Brindar representación legal a las víctimas del delito para que no se presente una situación de olvido por parte del sistema legal; b) La recuperación de las lesiones físicas y psicológicas; y, c) Alcanzar una reintegración en la sociedad por parte de la víctima (PÉREZ SACUEDA, 2015, p.9).

\subsection{ES UN PROCESO REFLEXIVO}

El éxito de la justicia restaurativa radica en la posibilidad que se ofrece principalmente al infractor, de concientizarse del daño que ha causado: Al colocarlo frente a las consecuencias de sus acciones delictivas, éste tiene mayores posibilidades de sensibilizarse con el sufrimiento de la víctima, generando en él un fuerte sentimiento de culpa que ayudará en la reparación del daño. Esta fase 
trascendental en los procesos restaurativos, es determinante para lograr una mayor predisposición del infractor para asumir los compromisos tendientes a reparar los daños y el malestar social causado en los demás ciudadanos.

\section{Para PEREZ:}

[...] en la justicia restaurativa, el castigo es sustituido por la aceptación de la responsabilidad de los hechos y por la búsqueda de métodos de reparación del daño causado. Lo anterior requiere de la participación activa en el proceso restaurador tanto del ofensor como de la víctima y en su caso, de terceros interesados en que las cosas lleguen a buen puerto (PÉREZ SACUEDA; ZARAGOZA HUERTA, 2015, p.2) ${ }^{8}$.

En ese sentido, existe una estrecha relación entre reflexión-reparación en el caso del infractor, pues a mayor reflexión habrán mayores posibilidades de lograr la reparación del daño causado, puesto que el infractor tendrá mayor predisposición y voluntad para cumplir los compromisos asumidos para tal fin.

Esta característica de la justicia restaurativa permite además centrar el enfoque en la magnitud del daño que ha padecido la víctima como consecuencia de la acción delictiva, y que al ser mostrado crudamente al infractor genera conciencia y arrepentimiento. De ahí que la necesidad de reflexión alcance no sólo al infractor sino también a la víctima y a la comunidad en general. Implica una pausa, un momento que permitirá apreciar el conflicto y analizar sus consecuencias presentes y futuras.

En el caso de la víctima, la justicia restaurativa como indica SUBIJANA, facilita la compresión de lo ocurrido, es decir "(...) de manos de quien fue su autor, por qué se les victimizó, lo que lo que les permite, en algunos casos, comprender el

\footnotetext{
${ }^{8}$ VAN NESS señala que, para esto se requiere que los delincuentes tomen la responsabilidad de sus actos y del daño que causaron y busquen en conjunto con las víctimas, y los miembros del entorno social su reintegración a la sociedad, Cfr., FRÍAS ARMENTA; ÁLVAREZ-HERNÁNDEZ, 2015, p. 7.
} 
sentido que en su devenir vital tiene ser víctimas de un delito, recuperando márgenes de seguridad existencial perdidos por la infracción penal" ${ }^{\prime}$.

El proceso restaurativo permite a la víctima recapacitar por qué razón fue ella y no otra persona la que padeció el daño, entender el motivo que impulsó al infractor a violentarla, también ayuda a recapacitar sobre si tomó o no las mínimas precauciones antes de sufrir el daño, entender la importancia de lograr una solución como medio para prevenir y recuperar la confianza en el entorno social.

Por otro lado, la ocurrencia del delito también es un episodio que genera la necesidad de reflexión en la comunidad, ya que marca el inicio para proponer y poner en marcha planes de prevención para evitar futuros delitos, y principalmente, para emprender la efectiva reparación de la relaciones dañadas.

Es importante destacar que este espacio reflexivo es la mejor forma de contribuir a la sanación de las relaciones sociales afectadas por el delito: El infractor, la víctima y la comunidad, deben comprender y ser conscientes, de la causa y magnitud de la acción delictiva, así como de la necesidad que hay de reparar el daño que fue generado.

De esta forma, infractor, víctima y comunidad, se hallan ligados, cada cual desde su contexto particular, por la necesidad de comprender y reflexionar sobre lo ocurrido y la búsqueda de la mejor forma de reparar el daño.

Sobre este tema, SUBIJANA postula la idea de la "recreación del vínculo dañado", lo que supone transitar de la ruptura causada por el delito a la pacificación integradora ofrecida por la solución, señalando que:

[...] con ello se tutela a la víctima -que obtiene una reparación del daño a partir de una aportación personal de su causante-, se mejora el tejido social -al acoger a personas que confían en la aptitud del ser humano para comprender el sentido dañino de los hechos injustos y desarrollar un esfuerzo para proceder a su reparación-, y, finalmente, se posibilita una

${ }^{9}$ SUBIJANA ZUNZUNEGUI, 2012, p. 148. Además precisa este autor que a la víctima le traslada que el daño injusto que ha sufrido no es fruto del azar o de un caso fortuito sino consecuencia del comportamiento de una o varias personas. Por ello le reconoce el derecho a ser reparada. 
protección de las víctimas potenciales (SUBIJANA ZUNZUNEGUI, 2012, p.149).

La justicia restaurativa como proceso reflexivo, marca una clara diferencia con el sistema penal retributivo, donde los formalismos, la existencia de procesos complejos y de larga duración, aunada a la intervención de intermediadores (jueces, fiscales, abogados, psicólogos, y demás personal técnico y administrativo), imposibilita para el agente lesivo, la posibilidad de conocer y de sensibilizarse con la víctima por el daño que le ha causado.

En los sistemas tradicionales de justicia, existen diversas barreras que impiden la mutua observación y la comunicación directa entre víctima y victimario, es por esta razón, que la reparación de las secuelas dejadas por el delito en la víctima y la sociedad, difícilmente son revertidas.

Por el contrario, como señala ZEHR la justicia restaurativa:

[...] facilita que el autor asuma la responsabilidad por sus actos y por el daño que ha causado. No le permite esconderse tras su abogado, al contrario de lo que sucede en la justicia ordinaria, en la que el abogado habla por él, lo niega todo y a veces intenta culpabilizar a la víctima como forma de que su cliente salga indemne del proceso (RULLAN CASTAÑER, 2011, p.9).

\subsection{ES UN PROCESO RESTITUTIVO}

La restitución del daño causado en su total magnitud constituye uno de los fundamentos esenciales de la justicia restaurativa y que lo particulariza de los modelos tradicionales de justicia. Lo que se busca es la "reparación integral del daño causado" a la víctima, lo cual incluye no sólo la atención del daño físico y psicológico, el reconocimiento de las pérdidas materiales, sino también el adecuado acompañamiento y atención moral de la víctima. 
La justicia restaurativa procura la reparación del daño, partiendo de la noción de que el delito es un hecho nocivo que ha generado un daño con diversos efectos y magnitudes, y reconociendo que es vital la participación de la víctima, el infractor y la comunidad para lograr restituir, de la manera más integral posible, el estado de cosas anterior a la acción delictiva.

En este sentido FRIAS y ALVAREZ (2015, p.7) señalan que, "en principio la justicia restaurativa no define el crimen como una transgresión a una disposición legal, sino como la causa de un daño individual y social. Es por esto que el objetivo principal es tratar de reparar ese daño"10.

No debemos olvidar que la acción delictiva genera desde la perspectiva de la justicia restaurativa, un daño con diversos efectos y magnitudes no sólo para la víctima sino para el mismo infractor y la comunidad. Este es el peculiar enfoque de la justicia restaurativa respecto al delito. No sólo la víctima necesita ayuda, aunque es la prioridad, sino también el infractor, y la forma de hacerlo es otorgándole la oportunidad de participar en un proceso donde, además de respetarse sus derechos y recibir un tratado digno y humano, tiene la posibilidad de reconocer su responsabilidad por el daño ocasionado y de comprometerse a repararlo.

Esta tarea al realizarse a la luz de los ojos de la comunidad genera un medio de regeneración social efectivo, fortaleciendo la seguridad y el orden. Al respecto, LIEBMAN resume con precisión señalando que, "[...] la Justicia Restaurativa aspira restaurar el bienestar de las víctimas, agresores y la comunidad dañadas por el crimen, y así prevenir mayores ofensas" (HERNÁNDEZ ALARCÓN, 2015, p.3).

Por su parte, PEREZ describe que la reparación del daño causado comprende cuatro etapas: a) La disculpa (comprende el reconocimiento del daño, la emoción o expresión de culpa y la vulnerabilidad o cambio de poder en los roles de

\footnotetext{
10 Para BRITTO, la justicia restaurativa busca restaurar el lazo social dañado por la acción criminal en un proceso de reparación y reconciliación entre la víctima y el infractor, con la mediación de la comunidad, asimismo señala que se da un papel fundamental a la víctima a quien se repara el daño y responsabiliza al ofensor, además de darle la oportunidad de deshacer el daño y reconciliarse con la sociedad, Véase: BRITTO RUIZ, 2010, p. 14.
} 
víctima y ofensor), b) cambio de conducta del ofensor, c) generosidad del ofensor como muestra de una verdadera disculpa y d) restitución, en dinero o servicios, a la víctima por el daño realizado (PÉREZ SAUCUEDA; ZARAGOZA, 2015, p.13).

De esta manera, la justicia restaurativa cumple un rol restitutivo para con la víctima, al reponerle de los daños físicos y psicológicos, perjuicios materiales y el desamparo moral sufridos; para con el infractor, al permitirle que libre y voluntariamente se reconozca como responsable del daño, realice los compromisos asumidos y otorgue otras liberalidades, para resarcir el daño y logre su plena rehabilitación, y; para con la comunidad, la recomposición del conflicto contribuye a restablecer el orden alterado por la acción delictiva y se fortalece la prevención, no vía el castigo, sino mediante la difusión de la experiencia vivida por las partes y la comunidad en el proceso restaurativo.

\subsection{ES UN PROCESO HUMANO}

Otro aspecto resaltante de la justicia restaurativa es que permite dar un trato humano a todos los intervinientes del conflicto, con la consigna de que la víctima y el infractor, bajo el aval de la comunidad, son los más interesados y directamente beneficiados con la solución efectiva del conflicto delictivo. En este escenario, lo más importante es el respeto de los derechos e intereses de las partes, lo cual resulta vital para el éxito del proceso restaurativo.

De este modo, lo que predomina para la justicia restaurativa es la humanización del proceso: Brindando un trato digno y respetuoso a la libertad y voluntad de las partes, garantizando sus derechos, intereses y necesidades.

En los sistemas penales retributivos, los excesivos procedimientos, formalidades y plazos, no hacen otra más cosa que distanciar a las partes, obstaculizando las posibilidades de resolver directamente el problema y además, despersonalizando el conflicto. Las partes intervinientes dejan de ser personas, el 
hombre se cosifica, se convierte en un número más en las estadísticas, en un caso más, resuelto o por resolver. Las partes a menudo se hallan privadas de sus derechos elementales ${ }^{11}$.

El carácter humano de la justicia restaurativa tiene su mayor fortalecimiento en el interior del proceso restaurativo, donde las partes liberadas de las formalidades y ataduras, participan libre y voluntariamente de un intercambio constante de información, que les permite entender los motivos y las consecuencias de la acción delictiva, la posibilidad arrepentimiento y perdón. Todas estas situaciones permiten humanizar a la víctima, al infractor y miembros de la comunidad, sensibilizándolos y concientizándolos sobre el problema, constituyendo un elemento central en la recomposición social.

Para SUBIJANA la "comprensión de lo ocurrido" en el proceso restaurativo ayuda en la tarea de humanización, pues permite a las partes narrar lo sucedido desde su particular situación. A las víctimas, les permite conocer quien fue su autor y por qué se le victimizó, comprendiendo las razones de ello y recuperando los márgenes de seguridad perdidos por la infracción penal. A los infractores, narrar lo ocurrido les permite percibir directamente las consecuencias que el delito ha provocado en la vida de las víctimas, favoreciendo su vinculación emocional con lo ocurrido (SUIJANA ZUNZUNEGUI, 2012, p.148).

Efectivamente, la justicia restaurativa es un proceso humano que ofrece a las partes la posibilidad de resolver el conflicto delictivo pero a partir de un proceso de profunda sensibilización y concientización, donde los protagonistas tienen la posibilidad de compartir mutuamente sus miedos, traumas, frustraciones,

\footnotetext{
${ }^{11} \mathrm{Al}$ respecto BECCARIA señala que, no hay libertad cuando algunas veces permiten las leyes que en ciertos acontecimientos el hombre deje de ser persona y se repute como cosa,Cfr., HIDALGO PORRAS, Natalia; Ob. cit., p. 35. Para FRIAS y ALVAREZ, la justicia restaurativa en teoría proclama los mismos objetivos de desarrollo social. El aumento de la calidad de vida, la participación comunitaria, el respeto a los derechos humanos, la equidad y la justicia son fundamentales para ambas. Lo fundamental es la calidad de las relaciones humanas mediante los procesos cooperativos en lugar de la intervención coercitiva del estado, Cfr., FRÍAS ARMENTA; ÁLVAREZ-HERNÁNDEZ, 2015, p.10-11.
} 
preocupaciones y necesidades. Ello genera mayor convicción en la tarea de reparación del daño y promueve la prevención a partir de la experiencia vivida por las partes.

Sobre este asunto, PEREZ y ZARAGOZA (2015, p.1) señalan que la justicia restaurativa, "representa una respuesta evolucionada al crimen, que respeta la dignidad y la equidad de cada persona, construyendo comprensión y promoviendo la armonía social, a través de un proceso de sanación de las víctimas, los ofensores y la comunidad". Así pues, la justicia restaurativa genera un centro de reflexión en torno al delito y sus consecuencias, permitiendo a las partes elaborar la mejor alternativa de solución.

\section{LOS PROGRAMAS RESTAURATIVOS EN LA REPARACIÓN DE LAS VÍCTIMAS}

\subsection{DEFINICIÓN Y FINALIDAD}

La justicia restaurativa para efectivizar sus principios esenciales y concretar sus objetivos, hace uso de determinados mecanismos o procedimientos a través de los cuales busca la reparación integral del daño causado por el hecho delictivo.

Los instrumentos que permiten la realización concreta de la justicia restaurativa, se denominan "programas restaurativos", concepto que ha sido definido por las Naciones Unidas como: "todo proceso en que la víctima, el delincuente y, cuando proceda, cualesquiera otras personas o miembros de la comunidad afectados por un delito participen conjuntamente de forma activa en la resolución de las cuestiones derivadas del delito, por lo general con la ayuda de un facilitador". Así, para las Naciones Unidas, programa restaurativo es todo aquel esquema en el 
cual se utilizan procesos restaurativos y se intenta lograr resultados restaurativos (ONU, 2007, p.7).

Conforme a lo señalado, los programas restaurativos están conformados por un conjunto de prácticas que involucran la participación plural de víctima, infractor y comunidad, y que mediante labores de cooperación e intercambio de información relevante sobre la acción delictiva y sus alcances, buscan alcanzar una solución integral y efectiva frente al daño causado por el delito. La necesidad de que exista una fuerte conexión reflexiva entre las partes intervinientes respecto al daño existente, es vital para la posterior definición y ejecución de acuerdos reparatorios.

En este sentido se ha señalado que los programas de justicia restaurativa se basan en la creencia de que son las partes del conflicto quienes deben involucrarse activamente para resolver y mitigar sus consecuencias negativas, así como en la intención de regresar a la toma de decisiones local y a la construcción de la comunidad (ONU, 2007, p.5).

La preocupación central de los programas restaurativos es la atención de la víctima afectada por el delito, la búsqueda de los medios para reparar el daño y la adopción de mecanismos para prevenir hechos similares. El logro de estos objetivos radica en la mayor predisposición de las partes durante las fases del proceso restaurativo.

Esta sencilla pero eficaz fórmula es la que diferencia a la justicia restaurativa de los procesos penales retributivos, donde la preocupación principal es la identificación del responsable del delito, la determinación e imposición de una sanción ejemplar a los ojos de la comunidad, pues a mayor daño causado por el delito, deberá corresponder mayor sanción al infractor, lo que además servirá de elemento disuasorio para el resto de la comunidad.

Por el contrario, los programas basados en la justicia restaurativa, "se basan en el principio fundamental de que el comportamiento delictivo no solamente viola la ley, sino también hiere a las víctimas y a la comunidad. Cualquier esfuerzo para 
solucionar las consecuencias del comportamiento delictivo deberá, en la medida de lo posible, involucrar tanto al ofensor como a las partes ofendidas, y proporcionar la ayuda y el apoyo que la víctima y el delincuente requieren" (ONU, 2007, p.6).

Para la justicia restaurativa, la existencia del delito supone fijar el foco de atención en la magnitud del daño que ha causado en la víctima y la comunidad, antes que la búsqueda de una sanción como reacción inmediata. Por ello, la participación y colaboración de la víctima, el infractor y la comunidad resulta sumamente vital para alcanzar la solución deseada por la justicia restaurativa: reparar integralmente el daño causado.

La forma de lograr la reparación del daño causado es mediante distintos programas de justicia restaurativa, donde los elementos subjetivos, víctima, infractor y comunidad, deben ser adecuadamente organizados y direccionados hacia el logro del objetivo fundamental, la reparación integral del daño ${ }^{12}$.

En este sentido CLASSEN destaca como principios de la justicia restaurativa el hecho de que se prefiere responder al crimen lo más pronto posible, con la máxima cantidad de voluntad y cooperación y el mínimo de coerción, ya que la reparación de las relaciones y los nuevos aprendizajes requieren de procesos de voluntad y cooperación; y además, siendo el proceso restaurativo un asunto fundamentalmente comunitario, se involucra la participación de todos los interesados, además del ofensor y la víctima (CARVAJAL PARDO, 2010, p.26).

Para alcanzar operatividad y efectividad, los programas restaurativos utilizarán diversos "procesos restaurativos" a través de los cuales se buscará lograr "resultados restaurativos", que se traduce en la reparación integral del conflicto.

\footnotetext{
12 Para las Naciones Unidas, la justicia restaurativa es un proceso para resolver el problema de la delincuencia enfocándose en la compensación del daño a las víctimas, haciendo a los delincuentes responsables de sus acciones y también, a menudo, involucrando a la comunidad en la resolución del conflicto. La participación de las partes es esencial al proceso y enfatiza la construcción de relaciones y reconciliaciones así como el desarrollo de acuerdos en torno a un resultado deseado por las víctimas y los delincuentes, ONU, 2007, p. 7.
} 
En ese sentido CAMARA señala que para la consecución de estos fines se utilizará fundamentalmente, programas de reconciliación entre víctima y ofensor, procesos de mediación -principal instrumento y "lugar natural" de la justicia restaurativa-, medidas de restitución del daño causado y sistemas de compensación (CAMARA ARROYO, 2011, p.9-10). Estos son algunos de las medios más usados en programas basados en la justicia restaurativa.

Por otro lado, los programas restaurativos buscan lograr un "resultado restaurativo", que ha sido definido en los siguientes términos:

Es un acuerdo alcanzado como resultado de un proceso restaurativo. El acuerdo puede incluir remisiones a programas como el de la reparación, el de la restitución y el de los servicios comunitarios, encaminados a atender las necesidades y las responsabilidades individuales y colectivas de las partes, y a lograr la reintegración de la víctima y del delincuente (ONU, 2007, p.7).

El acuerdo logrado por medio del proceso restaurativo, no sólo se limita a establecer compromisos del infractor frente a la víctima, sino también del infractor frente a la comunidad, pues el daño causado por la acción delictiva genera consecuencias tanto para la víctima como para la colectividad.

Por ello, para SUBIJANA el compromiso comunitario exige, "una involucración de la sociedad en la tarea de reconstrucción de lo deteriorado por el delito, pues la infracción es, también, un conflicto social que la comunidad tiene que resolver con la mayor eficacia y la menor aflicción" (SUBIJANA ZUNZUNEGUI, 2012, p.149).

\subsection{CARACTERÍSTICAS DE LOS PROGRAMAS RESTAURATIVOS}

El manual sobre programas de justicia restaurativa de las Naciones Unidas (2007, p.7), ha establecido como principios de los programas restaurativos los siguientes: 
a) Una respuesta flexible a las circunstancias del delito, el delincuente y la víctima que permite que cada caso sea considerado individualmente; b) Una respuesta al crimen que respeta la dignidad y la igualdad de cada una de las personas, desarrolla el entendimiento y promueve la armonía social a través de la reparación de las víctimas, los delincuentes y las comunidades; c) Una alternativa viable en muchos casos al sistema de justicia penal formal y a sus efectos estigmáticos sobre los delincuentes; d) Un método que puede usarse en conjunto con los procesos y las sanciones de la justicia penal tradicional; e) Un método que incorpora la solución de los problemas y está dirigido a las causas subyacentes del conflicto.

Como podemos apreciar, el centro de estos principios radica en la preocupación por buscar la reparación del daño ocasionado por el delito, otorgando a los afectados la posibilidad de alcanzar una solución que es más efectiva, sincera, directa y cuyo cumplimiento está garantizado por el propio responsable y la comunidad.

En este sentido BILBAO (2013, p.202) señala que:

[...] un modelo de justicia restaurativo busca el protagonismo de todos los implicados, dando prioridad a la víctima, relativiza la centralidad del castigo como expresión casi única de la ejecución de la justicia, subraya las virtualidades de la relación y el encuentro y posibilita una legitimación social de la legalidad mucho mayor.

\subsection{OBJETIVOS DEL PROGRAMA RESTAURATIVO}

Los programas restaurativos, en concreto, también tienen determinados objetivos a través de los cuales se pretende lograr un resultado restaurativo, y con ello la reparación de los daños ocasionados por la acción delictiva. En este sentido, se han establecido como objetivos los siguientes:

a) Apoyar a las víctimas, darles una voz, motivarlas a expresar sus necesidades, permitirles participar en el proceso de resolución y ofrecerles ayuda. Durante la últimas dos décadas aproximadamente, los sistemas de justicia penal se han enfocado más directamente en las necesidades e 
intereses de las víctimas. b) Reparar las relaciones dañadas por el crimen, en parte llegando a un consenso sobre cómo responder mejor al mismo. c) Denunciar el comportamiento criminal como inaceptable y reafirmar los valores de la comunidad. d) Motivar la responsabilidad de todas las partes relacionadas, especialmente de los delincuentes. e) Identificar resultados restaurativos y directos. f) Reducir la reincidencia motivando el cambio en los delincuentes particulares y facilitando su reintegración a la comunidad. g) Identificar los factores que causan el delito e informar a las autoridades responsables para que implementen estrategias de reducción del delito.

El tratamiento del delito a través de los distintos programas restaurativos, se enfoca en la necesidad de resolver el daño causado por el delito de una manera integral y sincera, con la participación conjunta de víctima, infractor y la comunidad. La construcción de una alianza entre los afectados por el delito, ayuda en la reconstrucción de los lazos dañados entre víctima e infractor, y fortalece las relaciones sociales en la comunidad, donde quedará evidenciado que se llegó a una efectiva y eficiente solución.

\subsection{PARTICIPANTES DEL PROGRAMA RESTAURATIVO}

Los programas restaurativos necesariamente requieren de la participación de las partes directamente involucradas, es decir del causante del daño o autor de la acción delictiva, y de la parte que ha padecido las consecuencias de esta acción, es decir la víctima.

Respecto a estos dos actores, la justicia restaurativa ha tenido sumo cuidado a fin de evitar caer en algún tipo de estigmatización hacia las partes, tanto para tratar de disminuir aún más la situación de desamparo y sufrimiento en el caso de la víctima, como para hacer alguna referencia superlativa a la conducta ya cuestionada del infractor. Por ello, los programas restaurativos comúnmente utilizan las denominaciones de ofendido y ofensor para referirse a la víctima y al infractor. 


\subsubsection{El ofendido}

El ofendido en el contexto de los programas restaurativos es la persona que ha padecido el daño como consecuencia del delito, es quien ha sufrido las lesiones físicas y psicológicas, quien ha perdido sus bienes y debe asumir los daños materiales. El ofendido, es además quien debe hacer frente directamente o por intermedio de otra persona, al responsable para pedir ser reparado por sus derechos violentados.

Es decir, uno es víctima no sólo por el estatus mismo de agraviado o sujeto pasivo al momento del delito, sino también, uno debe asumir este rol durante toda una fase posterior de reclamación para ser reparado. Muchos sistemas tradicionales de justicia, terminan por infligir a la víctima un doble padecimiento al someterla a procesos llenos de formalidades, trabas y dilaciones, configurándose una "doble victimización" del ofendido, la sufrida al momento del delito y la que debe soportar posteriormente, al reclamar y pedir justicia ${ }^{13}$.

Una de las justificaciones de la justicia restaurativa ha sido precisamente la necesidad de brindar tutela urgente a la víctima, acortando la distancia entre el daño sufrido y la reparación efectiva del mismo, a través de procesos que permiten la participación directa y voluntaria de las partes en la reparación del daño, en lugar de procesos que obstaculizan, con formalismos y plazos excesivos, la comunicación entre las partes y desalientan la conclusión de una pronta solución.

La especial situación en la que se halla el ofendido, lo coloca también en un espacio prioritario dentro del proceso restaurativo cuya razón de ser es justamente la de atender sus derechos, intereses, necesidades y expectativas. En los programas desarrollados bajo la justicia restaurativa como señala BILBAO (2013, p.202-203):

\footnotetext{
13 Justamente esta doble victimización es la que se busca evitar con los programas restaurativos, Cfr., NACIONES UNIDAS, 2007, p. 59. 
[...] el ofendido adquiere un protagonismo necesario e irrenunciable; además, se le reconoce una competencia y autonomía importantes en las cuestiones que le afectan $y$, por último, se atiende de una manera más adecuada, precisa y completa a sus derechos vulnerados y a las necesidades que le provocó la victimación.

El papel del ofendido en los programas de justicia restaurativa adquiere tal relevancia que sin su participación, aquellos carecen de mayor eficacia. Es por esta razón que la presencia del ofendido es vital ya que permitirá entender la magnitud del daño, facilitando la determinación de todo aquello que debe ser objeto de reparación.

Esta participación tiene una condición esencial, el ofendido debe intervenir en los programas restaurativos de manera libre y voluntaria, requisito que tiene incluso la categoría de principio de todo programa de justicia restaurativa: "Los procesos de justicia restaurativa deben usarse solamente con el consentimiento libre y voluntario de la víctima, y posteriormente, que la víctima debe tener la posibilidad de retirar su consentimiento y abandonar el proceso en cualquier momento" 14 .

El éxito del proceso restaurativo radicará en la libertad y voluntad de las partes, sobre todo del ofendido, quien tendrá mayor predisposición para dar a conocer en detalle sus aflicciones y necesidades, es decir, este elemento ayudará a comprender los detalles de las circunstancias en que se cometió el delito y las consecuencias para la víctima y su entorno social.

Podemos concluir que el ofendido en un programa restaurativo es:

a) La persona que ha padecido las consecuencias materiales, físicas, psicológicas, familiares y sociales del delito; b) La persona que, directamente o por intermedio de otra persona o institución, debe emprender un largo camino ante las instituciones para solicitar la reparación de los daños sufridos; c) La persona que, participando libre y voluntariamente de un proceso restaurativo, manifiesta la necesidad de ser reparada, compartiendo sus sufrimientos, temores, traumas y pérdidas, haciendo

${ }^{14}$ Cfr., NACIONES UNIDAS, 2007, p. 60. En este mismo sentido se ha señalado que es importante que las víctimas no se sientan forzadas a participar en el proceso de justicia restaurativa y que estén informadas sobre sus derechos a asesoría legal, cuando estén disponibles, y a retirarse del proceso en cualquier momento, (ONU, 2007, p. 61). 
evidente todo daño sufrido. d) La persona que, ha sido reparada por los daños sufridos, luego de haber participado en un proceso restaurativo. e) La persona que tiene entre sus prioridades superar el impacto causado por el delito.

\subsubsection{El ofensor}

El ofensor es causante del daño. En un proceso restaurativo los ofensores participan voluntariamente para conocer más de cerca las consecuencias que ocasionaron sus acciones en la víctima, con predisposición para reparar los daños ocasionados.

También se considera ofensor al responsable del daño causado. En este sentido LODE señala que:

[...] otro de los elementos de la justicia restaurativa es la responsabilidad del ofensor, pero desde el punto de vista activo. Este es invitado a tomar la responsabilidad activamente participando en las deliberaciones que se tornan para medir el daño causado y contribuir a la reparación del mismo (FRÍAS ARMENTA; ÁLVAREZ-HERNÁNDEZ, 2015, pp. 9-10).

$\mathrm{Ha}$ de advertirse que ser causante y responsable del daño son dos situaciones que si bien pueden configurarse al mismo tiempo como ocurre en la mayoría de casos, también habrán situaciones en las que el causante del daño sea una persona distinta a la persona que debe responsabilizarse del mismo. Este sería el caso de los niños o de personas privadas de todo discernimiento, quienes podrían ser los causantes del daño, pero la responsabilidad y posterior compromiso de reparación incluso dentro del proceso restaurativo serán asumidos por las personas responsables del cuidado de aquellos.

Fuera de situaciones excepcionales, los procesos restaurativos ofrecen al ofensor un escenario donde se prioriza un trato digno, igualitario y transparente, con respeto a sus derechos, donde se proscribe toda estigmatización, donde se le 
permite una intermediación directa con la víctima, donde puede asumir voluntariamente su responsabilidad por el daño ocasionado y donde luego de apreciar la real situación de la víctima, tiene mayor predisposición para reparar el daño y cumplir el compromiso comunitario en pro de su rehabilitación.

Para BILBAO (2013, p.202-203), la justicia restaurativa ofrece ciertos beneficios a los ofensores:

[...] se admite la posibilidad de su arrepentimiento y el consecuente cambio en su actitud; se favorece con más claridad y en mejores condiciones su reinserción social; se hace un reconocimiento de sus capacidades personales al tiempo que se interpela claramente a su responsabilización; en definitiva, se produce una humanización de la figura y la persona del delincuente.

Una situación distinta ocurre en los sistemas penales de corte retributivo. Los ofensores se hallan sujetos a una serie de estigmatizaciones como "denunciado", “delincuente", "investigado", "procesado", "encausado", "acusado", "sentenciado", "condenado", cuyo uso lamentablemente no concluye al término de la investigación o del proceso penal, sino que se incorporan posteriormente a la vida del ofensor y lo persiguen a donde vaya, desalentando sus posibilidades de rehabilitación.

Estos modelos tradicionales generan miopía en el ofensor al impedirle ver directamente la situación del ofendido luego del delito y apreciar la magnitud del daño que ha ocasionado, pues entre ofensor y ofendido hay una serie de barreras conformadas por procesos llenos de formalidades e intermediarios como abogados, fiscales, jueces, entre otros, que obstaculizan la real valoración del daño por parte del ofensor.

Al respecto, se señala que en el sistema de justicia penal convencional: 
[...] los delincuentes no solo tienen que confrontar las consecuencias completas de sus decisiones o de sus acciones. En muchos sistemas, un delincuente puede ser procesado, desde el arresto, la detención, el juicio, y la sentencia acaso hasta el encarcelamiento, sin proferir más que algunas oraciones (NAÇÕES UNIDAS, 2006, p.61).

Para BILBAO (2013, p.200), en estos sistemas, lo que importa verdaderamente es que se hace con el victimario y cuál es el castigo que corresponda imponerle y con cuyo cumplimiento se supone que se saldarán las deudas contraídas con la sociedad y sus víctimas.

El resultado que se aprecia en los modelos tradicionales de justicia, es un trato "despersonalizado" e "inhumano" de los ofensores, y que se traslada incluso luego de que han cumplido con la sanción impuesta, teniendo efectos en su propia rehabilitación, pues el sistema no ofrece ninguna posibilidad de regeneración, lo que prima es una situación de discriminación y exclusión social. El elemento clave que estuvo ausente en el ofensor sometido a este sistema, es el "compromiso" asumido libre y voluntariamente, para reconocerse como autor del daño, para repararlo y para cumplir las medidas tendientes a su rehabilitación ${ }^{15}$.

En los procesos restaurativos, la participación del ofendido es clave para conocer la magnitud del daño, y la intervención libre y voluntaria del ofensor también es indispensable no sólo para arribar a un acuerdo reparatorio, sino para que existan mayores posibilidades para su efectivo cumplimiento y con ello la plena satisfacción de la víctima y la comunidad.

El rol que cumple el ofensor en los procesos restaurativos está marcado no sólo por la necesidad de su participación, sino porque el éxito del resultado

\footnotetext{
${ }^{15} \mathrm{Al}$ respecto FRIAS y ALVAREZ señalan que con esto el ofensor adquiere un compromiso con la sociedad que le está dando la oportunidad de reconstruir su vida y al mismo tiempo la sociedad se compromete a ayudarle a reintegrarse. Los sistemas penales producen un efecto contrario al convertir a los delincuentes en mero receptores de una sentencia o castigo. Ellos no se comprometen con la sociedad, opuestamente son separados de ella y la reinserción a la sociedad queda en un segundo plano", Cfr., FRÍAS ARMENTA; ÁLVAREZ-HERNÁNDEZ, 2015, p. 10.
} 
restaurativo dependerá de la mayor predisposición que tenga el ofensor para reparar el daño y realizar las actividades de resocialización.

Para BILBAO (2013, p.202-203), estos beneficios:

[...] solo adquieren su auténtico sentido si el victimario asume los deberes y responsabilidades que supone participar en los procesos restaurativos, como son el de reconocer y reparar el daño causado, comprometerse a no provocar más dolor, rechazar la violencia y trabajar activamente para reconstruir las relaciones sociales.

El elemento central entorno al que gira el proceso restaurativo es la celebración y el cumplimiento de un "compromiso", que depende principalmente del ofensor. Par FRIAS y ALVAREZ (2015, p.11):

[...] el cumplimiento del compromiso que nace como parte en el acuerdo es tal vez aún más importante. Este segundo aspecto debe comprometer a los delincuentes directamente. Es aquí cuando demuestran que han aceptado la responsabilidad de su conducta y están preparados a responsabilizarse de manera real y práctica.

Podemos apreciar la relevancia de la participación del ofensor en dos espacios. Frente a la víctima, el ofensor facilitará el reconocimiento de la responsabilidad por el daño ocasionado y asumirá el compromiso de repararlo. Frente a la comunidad, el ofensor al comprometerse a realizar las actividades necesarias para su rehabilitación, genera mayor confianza y aceptación en su reinserción social.

Según lo descrito, podemos señalar dos características esenciales del ofensor dentro del programa restaurativo:

a) Ofensor es quien asume, libre y voluntariamente, la responsabilidad por el daño causado;

b) Ofensor es quien asume un compromiso frente a la víctima y frente a la comunidad. Ante la víctima, de reparar el daño ocasionado donde se incluyen los 
aspectos físicos, psicológicos y materiales. Ante la comunidad, de cumplir las medidas necesarias para su rehabilitación y reinserción.

\subsubsection{La comunidad}

Los programas restaurativos permiten la participación activa de la comunidad, para conducir el desarrollo de un determinado proceso restaurativo así como para brindar acompañamiento a las partes. No sólo se permite la participación de los familiares o amigos de las partes involucradas, sino también la intervención de determinadas personas representativas de la sociedad, como dirigentes vecinales, sacerdotes, representantes de asociaciones defensoras de los derechos humanos y derechos ciudadanos, ofendidos y ofensores que participaron en anteriores programas, profesionales y personas honestas y con elevadas cualidades éticas; todos ellos con la capacidad de conducir, facilitar y aportar positivamente en todo proceso restaurativo.

La justicia restaurativa busca que el tratamiento del delito, que incluye la atención y acompañamiento del ofendido y del ofensor hasta llegar a una solución efectiva, se realice en un espacio comunitario, pues el delito al concebirse como un mal social, como un agravio con repercusiones colectivas, debe ser confrontado por la misma comunidad para encontrar la forma de reparar los desequilibrios de la acción delictiva.

En un escenario donde hay programas restaurativos exitosos, la comunidad cumple una función realmente importante, antes, durante y después del programa. En este sentido, se ha señalado que, "la comunidad asume un papel activo en respuesta al delito y a los conflictos y, al hacerlo, se fortalecen la capacidad de 
solucionar problemas, de control social informal y de cohesión social de la comunidad"16.

La participación dinámica de la comunidad la podemos observar a continuación.

\section{a) Antes del programa restaurativo}

La comunidad organizada en programas restaurativos, ofrece a la víctima del delito inmediata tutela y protección. De la misma manera, ofrece al ofensor la alternativa de poder encontrar una efectiva solución a través de un proceso restaurativo, donde podrá escuchar y ser escuchado. La decisión libre y voluntaria de las partes para participar del proceso restaurativo, determinará el inicio del mismo.

b) Durante el programa restaurativo

La comunidad tendrá especial actividad durante el desarrollo del programa restaurativo, donde se llevará a cabo el intercambio de experiencias entre ofensores y ofendidos, donde también participan facilitadores, capacitadores, intermediarios, familiares y amigos, autoridades, ofensores y ofendidos de programas anteriores, representantes de distintos sectores de la sociedad y toda persona dispuesta a colaborar.

Cada uno tendrá un rol determinado dentro del programa restaurativo que va desde la dirección (facilitadores), la educación (capacitadores, autoridades y profesionales), el acompañamiento y asistencia (amigos, familiares y grupos de

\footnotetext{
${ }^{16}$ NACIONES UNIDAS, 2006, p. 57. Hay una variabilidad considerable en la naturaleza y grado de la participación de la comunidad en varias metodologías de justicia restaurativa. Por ejemplo, en la mediación víctima-delincuente (VOM) la comunidad está ausente y el proceso está compuesto por un mediador, el delincuente y la víctima. En sentencias en círculo, por otro lado, el proceso está abierto a todos los demás miembros de una comunidad local, villa o grupo nativo, p. 65.
} 
apoyo), la concientización y sensibilización (psicólogos, terapeutas, ofensores y ofendidos de programas anteriores).

La participación de estos miembros de la comunidad en el programa restaurativo facilitará el camino para poder llegar a una solución eficiente entre las partes, esto es, reparar el daño y sus implicancias.

c) Después del programa restaurativo

La labor comunitaria no culmina con el resultado restaurativo o acuerdo reparatorio, sino que hay todo un camino de supervisión y observación posterior. Es necesario vigilar que el ofensor cumpla con sus deberes asumidos frente al ofendido y frente a la colectividad, y cuando hay desánimo o abandono parcial de los compromisos, la comunidad tendrá que brindar el apoyo necesario al ofensor para culminar su labor reparatoria. También, en caso el ofensor muestre renuencia o resistencia a cumplir sus compromisos, deberán adoptarse las medidas adecuadas para derivar el caso a los fueros ordinarios de justicia.

La importante labor de la comunidad en los programas restaurativos, puede ser descrita a partir de dos enfoques: Uno al que podemos denominar influencia comunitaria directa, referido a la participación de la comunidad en el desarrollo de todo el proceso restaurativo que comprende el inicio, su periodo de duración y la supervisión posterior del resultado restaurativo. El otro enfoque se refiere a la influencia comunitaria indirecta.

En primer lugar, la realización de un proceso restaurativo dentro de un grupo humano determinado, donde se ha logrado soluciones efectivas para las partes, sirve de efecto reflejo en el resto de la comunidad, donde se restituye la sensación de tranquilidad, seguridad y confianza, y se refuerza la prevención.

En segundo lugar, el bienestar devuelto a la comunidad a través del proceso restaurativo, también tendrá un efecto reflejo en el ofendido al mostrar solidaridad 
con su situación, ayudándolo a reincorporarse luego del trauma sufrido, pero sobre todo, también existirá una mayor predisposición para colaborar con la rehabilitación y la REINSERCIÓN SOCIAL DEL OFENSOR.

\section{CONSIDERACIONES FINALES}

a) La justicia restaurativa es una disciplina cuyo desarrollo y base se ha centrado en la necesidad de establecer mecanismos adecuados de tutela y reparación para las víctimas del conflicto, buscando su reparación integral, pero además, tratando de concatenar una solución que integre al responsable y a la comunidad en general, pues solo de esa manera es posible la restauración de las relaciones y derechos afectadas.

b) La justicia restaurativa tiene una base plurisubjetiva, pues son las partes involucradas las que conforman el primer elemento esencial, con particular interés, importa la atención y protección de la víctima, sin desconocer el aporte importante del responsable y el respaldo de la comunidad.

c) La justicia restaurativa tiene un base pluriobjetiva, compuesto por una serie de elementos relacionados al daño causado, pues habrá que establecer sus dimensiones, gravedad, afectaciones y finalmente a partir de ese proceso de identificación y determinación, establecer las medidas más adecuadas para buscar su reparación integral.

d) La justicia restaurativa es un proceso intersubjetivo que busca la coparticipación de la víctima, el responsable y el apoyo de la comunidad, donde existe pleno respeto a la libertad y a los derechos humanos de víctima e infractor; donde se busca la reparación integral del daño y de la afectación causada a la víctima, tratando de restituirle las afectaciones sufridas de una manera oportuna y efectiva. 
e) Los procesos restaurativos son los mecanismos que se han diseñado para hacer efectiva la reparación del daño causado, en ese sentido, requiere la intervención de las víctimas, de los infractores y de la comunidad, en atención al grado de participación, podrán haber programas restaurativos que involucren a todos los actores, algunos que trabajen solo con víctimas u otros con infractores, pero el objetivo central es la reparación integral, en especial del estatus de la víctima.

f) Los programas restaurativos facilitan la reparación de afectaciones a las víctimas y permiten otorgar espacios de tutela y reparaciones efectivas, de una forma integral que comprende no sólo el daño físico y económico,sino también las lesiones psicológicas y morales, durante y después de la ocurrencia del hecho vulneratorio, y es precisamente este objetivo central en la restauración de las relaciones afectadas, lo que distingue a la justicia restaurativa de cualquier otro mecanismo de solución del conflicto.

\section{REFERENCIAS}

ACOSTA TOBÓN, Sergio Andrés. "Impactos psicológicos de la justicia restaurativa en el marco de la ley de justicia y paz", En: Revista Electrónica de Psicología Social «Poiésis», № 18, Colombia, Diciembre de 2009.

ANGELUDIS TOMASSINI, Julissa. La Justicia Restaurativa como Mejor Alternativa. Editorial Grijley, Lima, 2012.

ARIAS MADRIGAL, Doris M. "Reflexiones teóricas y prácticas sobre la reparación del daño y la justicia restaurativa", En: $<w w w . c e e a d . o r g . m x / . . / 29$._reflexiones_sobre_reparacin_del_dao_y_justicia_restaur ativa_doris_arias.pdf>, revisado febrero de 2015, pp. 1-18.

BILBAO ALBERDI, Galo. "El desafío de la paz y la justicia restaurativa en sociedades divididas. El caso del País Vasco", En: Sociedad y Utopía, Revista de Ciencias Sociales, № 42, Madrid, Noviembre de 2013.

BRITTO RUIZ, Diana. Justicia Restaurativa, Reflexiones sobre la experiencia en Colombia, Universidad Técnica Particular de Loja, Loja, Ecuador, 2010. 
CAMARA ARROYO, Sergio. "Justicia juvenil restaurativa: marco internacional y su desarrollo en América latina", En: Revista de Justicia Restaurativa, № 01, Sociedad Científica de Justicia Restaurativa, Octubre de 2011.

CARVAJAL PARDO, Alejandro. "Justicia restaurativa: construyendo un marco englobador para la paz", En: Criterio Jurídico, Santiago de Cali, V. 10, No. 1, 2010.

CONSEJO NACIONAL DE SEGURIDAD CIUDADANA CONASEC. Plan Nacional de Seguridad Ciudadana 2013-2018, Lima, 2013, En: http://www.mininter.gob.pe/pdfs/Plan.Nacional. Seguridad.Ciudadana.2013-2018.pdf, visitado en febrero de 2015, pp. 1-159.

COSTELLO, Bob; WACHTEL, Joshua y WACHTEL, Ted. Manual de Prácticas Restaurativas para Docentes, Personal Responsable de la Disciplina y Administradores de Instituciones Educativas, Instituto Internacional de Prácticas Restaurativas, Pennsylvania, USA, 2011.

DUYMOVICH ROJAS, Ivonne M. La reparación Integral como Mejor Alternativa de Satisfacción a la Víctima: Experiencias de la Justicia Restauradora en Casos de Delincuencia Juvenil y Violaciones a los Derechos Humanos, Instituto de Ciencia Procesal Penal, Lima, 2007.

FRÍAS ARMENTA, Martha y ÁLVAREZ-HERNÁNDEZ, Jaime. "Desarrollo social y justicia restaurativa", En: <http:// www.juridicaformativa.uson.mx/memorias/v_coloquio/doc/penal/FRIAS_ARMENTA_ Y_ALVAREZ_HERNANDEZ.pdf>, visitado en febrero de 2015, pp. 1-15.

FRIEDMAN VOLOSKY, Loreley. Justicia Restaurativa. Nuevas Formas de Tratamiento para Delincuentes Juveniles, Instituto de Derecho Penal Europeo e Internacional, 2007.

GARZON VALDEZ, Ernesto. “¿Cuál es la relevancia moral del principio de la dignidad humana?, En: Derechos Fundamentales y Derecho Penal, Patricia Coppola, Coordinadora, Advocatus, Córdova, 2006.

GONZALES GONZÁLES, Dolly Yamile. AMAYA BARRERA, Néstor Gilberto y Fabio, CARDENAS ORTIZ. Justicia Restaurativa Frente a la Ley de Justicia de Paz y Ley de Víctimas en Colombia, Tesis, Universidad Libre, Facultad de Derecho Instituto de Postgrados, Maestría en Derecho Pernal, Bogotá, 2012. 
HENRY, Véronique. "La Justicia Juvenil Restaurativa en el Perú. El desafío de convertirse en política pública", En: Revista de Actualidad Jurídica Essentia luris, № 09, Enero, 2016.

HENRY, Véronique. "Justicia Juvenil Restaurativa en el Perú: En vías de convertirse en política pública”, En: Revista de Justicia Restaurativa, № 01, Sociedad Científica de Justicia Restaurativa, Octubre de 2011.

HERNÁNDEZ ALARCÓN, Christian. "Salidas Alternativas y Justicia Restaurativa en la Justicia Penal Juvenil", En Revista Virtual Teleley: $<$ www.teleley.com/articulos/art_080512.pdf>, revisado febrero 2015, pp. 1-24.

HIDALGO PORRAS, Natalia. La Justicia Restaurativa como Expresión del Principio de Última Ratio de la Pena en un Marco de Protección de los Derechos Humanos. Proyecto De Investigación, Universidad Estatal A Distancia, Sistema de Estudios de Posgrado, Maestría en Derechos Humanos, San José, Costa Rica, 2012.

MEDINA OTAZÚ, Augusto. "Necesidad de la política criminal en el sistema jurídico penal. Especial referencia al caso peruano", En: Revista Jurídica del Perú, Número 108, Febrero 2010.

MONTERO AROCA, Juan. Principios del Proceso Penal. Editorial Tirant Lo Blanch, Valencia, 1997.

NACIONES UNIDAS. Consejo Económico y Social -Comisión de Prevención del Delito y Justicia Penal; Justicia Restaurativa, Informe del Secretario General, Viena, Abril 2002.

. Oficina de Drogas y Crimen. Manual sobre Programas de Justicia Restaurativa. Nueva York, 2006.

ORGANIZACIÓN DE LAS NACIONES UNIDAS - ONU. Recopilación de Reglas y Normas de las Naciones Unidas en la Esfera de la Prevención del Delito y la Justicia Penal. Oficina contra la Droga y el Delito, Nueva York, 2007.

PÉREZ SAUCEDA, José Benito y ZARAGOZA HUERTA, José. Justicia restaurativa: del castigo a la reparación, En <http://biblio.juridicas.unam.mx/libros /7/3104/38.pdf >, visitado en febrero de 2015.

RODRIGUEZ CHAVEZ, Reyler. "La justicia restaurativa como medio para efectivizar los derechos fundamentales",En: Revista de Actualidad Jurídica Essentia luris, № 12, Abril de 2016. 
"Alcances del programa de prevención "Justicia, Paz y Seguridad", En: Revista de Actualidad Jurídica Essentia luris, $N^{\circ}$ 09, Enero, 2016.

ROXIN, Claus. Política Criminal y Sistema del Derecho Penal. Traducido por Muñoz Conde, Francisco, Editorial Hammulrabi, Buenos Aires, 2002.

RULLAN CASTAÑER, Vicenc. Justicia y Prácticas Restaurativas, Los Círculos Restaurativos y su Aplicación en Diversos Ámbitos. Fundación Universitaria Iberoamericana, Maestría en Resolución de Conflictos y Mediación, Tesis, Palma España, Febrero de 2011.

SCHMITZ Jean. "Prácticas restaurativas", En: Revista de Actualidad Jurídica Essentia luris, № 09, Enero, 2016.

SILVA SÁNCHEZ, Jesús-María. Política criminal y Persona. editorial Ad-Hoc, Buenos Aires, 2000.

TAMARIT SUMALLA,Josep M. "La justicia reparadora en la ejecución penal ante las reformas penales", En: <http://www.yumpu.com/es/document/view/14873083/la-justicia-reparadora-en-laejecucion-penal-ante-las-reformas->, visitado en febrero de 2015, pp. 1-35.

TENTI FANFANI, EMILIO, "El oficio del maestro en el siglo XXI", En: Educación y Justicia: El Sentido de la Educación, TEDESCO, Juan Carlos Coordinador, Fundación Santillana, 2006.

TIERRA DE HOMBRES. Aprender de experiencias para Transformar Realidades. Capitalización de Experiencias en Justicia Juvenil Restaurativa del Ministerio Público y la Fundación Terre Des Hommes - Lausanne, Lima, 2015.

. Justicia para Crecer, № 01, Noviembre 2005- Febrero 2006, Lima-Perú. . Justicia para Crecer, $\mathbf{N}^{\circ}$ 20, Diciembre 2015, América Latina. . Justicia para Crecer, $\mathbf{N}^{\circ} 19$, Mayo 2014,

TREJO ESCOBAR, Miguel Alberto; "La ley penal juvenil salvadoreña y la Justicia restaurativa", En: Revista de Justicia Restaurativa, № 01, Sociedad Científica de Justicia Restaurativa, Octubre de 2011. 